\title{
Hyperventilation in men claiming compensation for benign asbestos-related diseases
}

\author{
GK Crompton \\ Retired Consultant Physician, Western General Hospital, Edinburgh; Part-time Senior Lecturer, Department of Respiratory Medicine, \\ University of Edinburgh; and Former Part-time Medical Member of the Lord Chancellor's Department
}

\begin{abstract}
The observation that hyperventilation was common in men involved in civil court actions compared with my non-medico-legal practice stimulated me to carefully assess 100 consecutively seen men with non-malignant asbestosrelated disease(s). A diagnosis of hyperventilation was made in 33 and probable hyperventilation in 12. The development of anxiety symptoms in these men could, in part at least, be prevented or greatly decreased if more emphasis was placed on the education of ex-asbestos workers by solicitors and organisations responsible for the initiation of civil actions.
\end{abstract}

Correspondence to GK Crompton, 14 Midmar Drive,

Edinburgh EHIO 6BU, UK

tel. +44 (0) I3I 4471022

e-mail gkcromp@hotmail.co.uk

KEYWORDS Benign asbestos-related diseases, civil action, expert medical reports, hyperventilation, Social Security benefits, sensation of breathlessness

DECLARATION OF INTERESTS No conflict of interests declared.

\section{INTRODUCTION}

The diverse clinical presentations of hyperventilation were first described in 1937 and the term hyperventilation syndrome (HVS) was coined in 1938. ${ }^{2}$ Doctors and many lay people are familiar with over-breathing associated with acute emotional reactions, classically displayed by adolescent or young adult females; however, there is a much more subtle form of disorder related to disturbed breathing which is frequently not suspected, ${ }^{3}$ but an accurate assessment of the frequency of this in disease states or the normal population is unknown. When it is a complication of organic disease, "breathlessness' of hyperventilation is frequently misinterpreted by the patient and clinician as a manifestation or deterioration of the organic disease, and direct questioning may be needed to elicit that attacks of breathlessness occur at rest for no apparent reason or that the breathlessness on exertion is poorly related to the severity of exertion. ${ }^{3}$

It has been my experience that hyperventilation or dysfunctional breathing is common in men involved in civil actions because of asbestos-related conditions. I saw these patients as a medical expert commissioned to write reports for civil action purposes. The frequency of my diagnosis of anxiety/hyperventilation stimulated me to examine my records in order to assess the magnitude of this problem.

\section{MATERIALS AND METHODS}

The reports and records of 100 men seen consecutively between March 2003 and April 2009 who had pleural plaques and/or diffuse pleural thickening and/or asbestosis were used for this analysis.
TABLE I Diagnostic criteria

\begin{tabular}{|l|}
\hline $\begin{array}{l}\text { Sensation of breathlessness completely different } \\
\text { to exercise-induced breathlessness experienced } \\
\text { in the past }\end{array}$ \\
\hline $\begin{array}{l}\text { I. Sensation of having to take extra-deep breaths and } \\
\text { frequent yawning }\end{array}$ \\
\hline $\begin{array}{l}\text { 2. Sensation of not being able to get enough air/oxygen } \\
\text { into the lungs }\end{array}$ \\
\hline Associated symptoms \\
\hline - Pins and needles in hands when 'breathless' \\
\hline - Cramps in hands and fingers when 'breathless' \\
\hline - Dizziness brought on by 'breathlessness' \\
\hline - A feeling of panic when 'breathless' \\
\hline - Chest discomfort associated with 'breathlessness' \\
in the absence of ischaemic heart disease \\
\hline - A feeling of being short of breath at rest or during \\
conversations, especially on the telephone
\end{tabular}

My detailed notes and expert reports of men with nonmalignant asbestos-related diseases, made after clinical examination and scrutiny of general practitioner (GP) records, hospital records and relevant legal and Department of Health and Social Security documents, ${ }^{4}$ were examined and the following information was extracted: age, asbestos-related condition(s), other significant diseases and the presence or absence of symptoms suggesting hyperventilation. Reports prepared after an examination of medical records only (desktop reports) were excluded from the study as were those of all patients who had, or were thought to have, malignant disease, usually mesothelioma or lung cancer. None were considered to have an asbestos-related disease that would greatly decrease life expectancy. 
A diagnosis of hyperventilation was made using the criteria in Table I. These criteria were adopted because they have been described and accepted as being typical features of HVS. ${ }^{1,3}$ In addition, all men had to have told me, in response to direct questioning, that their sensation of breathlessness was completely different to exerciseinduced breathlessness experienced in the past, ${ }^{5}$ and most also admitted to sensations I and/or 2 (Table I). These cases were labelled as probable hyperventilation. When one or more of the associated symptoms listed were present a diagnosis of hyperventilation was accepted.

\section{RESULTS}

The age range of the 100 men was 54 to 87 . Hyperventilation was diagnosed in 33 and probable hyperventilation in 12. The asbestos-related diagnostic categories were:

- Pleural plaques alone (16)

- Pleural plaques and asbestosis (49)

- Pleural plaques and diffuse pleural thickening (6)

- Pleural plaques, diffuse pleural thickening and asbestosis (8)

- Diffuse pleural thickening alone (16)

- Diffuse pleural thickening and asbestosis (5)

There were no cases of asbestosis in the absence of pleural disease.

Other medical conditions were listed if they were likely to be the cause of breathlessness, such as chronic obstructive pulmonary disease (COPD) and asthma; or have an adverse effect on life expectancy, such as cerebro-vascular disease and diabetes; or were responsible for distressing non-respiratory symptoms at the time of the examination, such as cervical spondylosis, lumbar spinal stenosis and rheumatoid disease. The average number of such conditions for each man is given in Table 2 under the heading of 'associated diseases'.

\section{DISCUSSION}

This analysis confirmed my impression that a large number of men (45\%) with asbestos-related diseases also had hyperventilation or probable hyperventilation. All appeared to have developed hyperventilation as a result of being informed that they had a problem related to industrial exposure to asbestos in the past. A few had a previous history of anxiety/depression, but there was no indication of possible hyperventilation in the medical records. Most were given inadequate information about the nature and prognosis of their asbestos-related condition and the majority were under the impression that they would die because of it. In most men their hyperventilation was the cause of much more distress than their asbestos disorder(s).
TABLE 2 Patients with hyperventilation in the asbestos disease categories and average number per man of associated diseases

\begin{tabular}{|l|l|l|l|}
\hline & Total & Hyperventilation & $\begin{array}{l}\text { Associated } \\
\text { diseases } \\
\text { (average) }\end{array}$ \\
\hline Pleural plaques & 16 & $9(50 \%)$ & 0.75 \\
\hline $\begin{array}{l}\text { Pleural } \\
\text { thickening }\end{array}$ & 16 & $10(62.5 \%)$ & 0.7 \\
\hline $\begin{array}{l}\text { Pleural plaques } \\
\text { and asbestosis }\end{array}$ & 49 & $14(28.6 \%)$ & 1.6 \\
\hline $\begin{array}{l}\text { Pleural } \\
\text { thickening and } \\
\text { asbestosis }\end{array}$ & 5 & $5(100 \%)$ & 2.2 \\
\hline $\begin{array}{l}\text { Pleural plaques } \\
\text { and pleural } \\
\text { thickening }\end{array}$ & 6 & $2(33 \%)$ & 1 \\
\hline $\begin{array}{l}\text { Pleural plaques, } \\
\text { pleural thickening } \\
\text { and asbestosis }\end{array}$ & 8 & $5(62.5 \%)$ & 2.2 \\
\hline Total & 100 & 45 & \\
\hline
\end{tabular}

There does not appear to be a correlation between the type or severity of asbestos-related disease and the development of functional breathing problems. Unfortunately, I did not keep a note of whether a diagnosis of hyperventilation had been made prior to my examination by physicians involved in the civil actions, but I can say that this was rarely the case. Perhaps it was not considered to be in the pursuers' interests, by the physicians preparing reports on their behalf, to make a diagnosis of non-organic breathlessness, since this would decrease the estimated respiratory disability considered to be caused by the asbestos-related disease(s). In addition, it is extremely difficult to estimate respiratory disability when faced with a combination of organic and non-organic causes of respiratory distress.

More than $90 \%$ of my reports were commissioned by solicitors representing the defenders of civil actions. This meant that the majority of men I examined had also been examined by at least one other medical expert as well as their GP and in most cases a Benefits Agency physician in relation to a claim for a Prescribed Disease Industrial Disablement Benefit. Many had also been advised by solicitors and associations such as the Clydeside Action on Asbestos. One would expect that because of all the contact with clinicians and nonmedical asbestos-related disease experts, the patients would have picked up accurate information about their asbestos problem. This, however, was far from the case. Common misconceptions were:

- Fatal outcome. The majority of men believed that their asbestos condition would considerably shorten their lives, and some spoke in terms of weeks or months. 
- The fact that a civil action was in process indicated to them that they must have a very serious medical condition caused by previous exposure to asbestos.

- Asbestosis is the name given to all types of asbestosrelated diseases. Very few men knew the difference between the different types of asbestos-related diseases and considered them all to be asbestosis.

- Pleural plaques are actually sheets of asbestos in the chest.

- Pleural plaque disease is progressive and is likely to change into mesothelioma.

- Respiratory disability expressed as a percentage reflected the amount of lung tissue destroyed by the asbestos condition.

Most men with hyperventilation suffered much more distress because of this non-organic problem than because of any organic disease. Indeed, most of the patients I saw had few or no symptoms caused by their asbestos conditions. This is exemplified by the development of hyperventilation in nine of the 16 men with pleural plaques alone, since two were otherwise completely fit and the only medical problems in another two were obesity and anxiety (Table 3 ).

In my view it is unlikely that the breathing dysfunction I have diagnosed as hyperventilation was caused by simple anxiety resulting from the procedures involved in a civil action or exaggeration of symptoms in order to obtain greater compensation. All the men diagnosed as having hyperventilation or possible hyperventilation admitted that the sensation of breathlessness they had developed was completely different from exercise-induced dyspnoea experienced in the past. I believe that this is the most important question to be asked when a diagnosis of hyperventilation is being considered, since it can distinguish true hyperventilation from a simple increase in dyspnoea caused by anxiety, etc.

A diagnosis of hyperventilation was never made when the only complaint was an increase in the sensation of 'normal' breathlessness previously experienced. All the men examined responded to direct questioning about their sensation of breathlessness. None, as far as I can recall, spontaneously volunteered that their breathing problem was different from previously experienced exertional dyspnoea. Bass and Gardner ${ }^{6}$ studied 29 patients with hyperventilation referred by specialist physicians and found that all but one complained of an 'inability to take a satisfying breath' which they described as air hunger, but they were unable to identify any other common feature. This adds weight to my observation that a change in the sensation of breathing is the diagnostic complaint of hyperventilation, but this usually has to be discovered by direct questioning since it is rarely volunteered spontaneously.
TABLE 3 Patients with pleural plaques but no other asbestos-related condition

\begin{tabular}{|l|l|}
\hline $\begin{array}{l}\text { Patients with pleural plaques but no other asbestos- } \\
\text { related condition }\end{array}$ & 16 \\
\hline Number with hyperventilation & 5 \\
\hline Number with possible hyperventilation & 4 \\
\hline $\begin{array}{l}\text { Associated medical conditions in the nine men with } \\
\text { pleural plaques and hyperventilation }\end{array}$ \\
\hline Age & Associated medical conditions \\
\hline 79 & None \\
\hline 80 & None \\
\hline 56 & Hypertension, ankylosing spondylitis \\
\hline 69 & Ischaemic heart disease \\
\hline 70 & Ischaemic heart disease, hypertension \\
\hline 63 & Ischaemic heart disease, peripheral neuropathy \\
\hline 54 & Obesity (body mass index [BMI] not recorded) \\
\hline 66 & Obesity (BMI 3I), anxiety/depression \\
\hline 78 & Ischaemic heart disease, COPD \\
\hline
\end{tabular}

The average number of associated diseases for all men considered to be giving rise to distressing symptoms at the time of examination, or considered likely to decrease life expectancy, was low (Table 2). The lowest incidence of hyperventilation of $28.6 \%$ was seen in the group of 49 men with pleural plaques and asbestosis, which suggests that the severity of asbestos-related disease was unlikely to be the main cause of the development of hyperventilation.

It is my impression that hyperventilation complicating a civil action causes such great distress that this cannot be compensated by any monetary award achieved as a result of the action. This is particularly the case since hyperventilation is not an easily treated condition and unfortunately in the cases about which I have been able to obtain follow-up information the hyperventilation tends to remain untreated, and also often undiagnosed since the civil action expert medical reports are not routinely available to GPs. It is, of course, possible that my diagnoses of hyperventilation have been incorrect and I have been guilty of over-diagnosis. I do not think that this is the case, but this is difficult to prove, since follow-up information of patients involved in civil actions is rarely available and follow-up examination rarely possible. In five cases referred for metabolic exercise testing my diagnosis of hyperventilation was confirmed.

It is difficult to explain why a high proportion of men with benign asbestos-related diseases develop hyperventilation. As far as I could make out, very little knowledge was provided for them by the solicitors acting on their behalf. The first people to give information and advice to the pursuers were usually solicitors and/ or GPs. This first contact is in my view pivotal since much of the anxiety generated by the diagnosis of an 
asbestos-related condition could perhaps be prevented if adequate personalised information and explanation about the condition(s) is provided on an individual basis given at the outset of the legal process. Unfortunately, it is apparent that many GPs do not understand the differences between the asbestos-related diseases and their prognoses, which makes the role of the solicitor even more important.

Action on Asbestos and similar associations have a very important role to play since many men are routed to a solicitor via these associations by hospital clinicians and GP referrals. The results of this survey suggest that these associations have so far failed in the education of men referred to them, but as far as I can determine these associations could and should take a much more active educational role in the future. Medical experts acting on behalf of the pursuers should, of course, be expected to provide more information for the men they examine. It is also apparent that few clinicians ask leading questions about the different sensation of breathlessness experienced by patients with breathlessness, and this, in my view, is the reason why hyperventilation is so frequently undiagnosed.

\section{REFERENCES}

I Kerr WJ, Dalton JW, Gliebe PA. Some physical phenomena associated with anxiety states and their relation to hyperventilation. Ann Intern Med 1937; I I:961-92.

2 Soley M, Shock N.The aetiology of effort syndrome. Am J Med Sci 1938; 196:840-51. doi:I0.1097/0000044I-1938I2000-00010

3 Howell JBL. The hyperventilation syndrome: a syndrome under threat? Thorax 1997; 52(Suppl 3):530-4. doi:10.I I36/thx.52.2008.S30

4 Department for Work and Pensions Social Security Administration Act 1992. Asbestos-related diseases. Report of the Industrial Injuries Advisory Council. London:The Stationery Office; 2005.

5 Crompton GK, Haslett C, Chilvers ER. Diseases of the respiratory system. In: Haslett C, Chilvers ER, Hunter JA et al., editors. Davidson's principles and practice of medicine. 18th ed. Edinburgh: Churchill Livingstone; 1999.

6 Bass C, GardnerWN. Respiratory and psychiatric abnormalities in chronic symptomatic hyperventilation. BMJ 1985; 290:1387-90. doi: I0.I I36/bmj.290.6479.1387

Hyperventilation is a common finding in men with nonmalignant asbestos-related diseases involved in civil actions, and is often overlooked by clinicians because its diagnosis depends on direct or leading questions being asked about the sensation of breathlessness. The onset of hyperventilation is usually triggered by anxiety which is often brought on by a lack of information about the asbestos conditions and their prognoses provided at the time of their first recognition. In many cases, the distress created by hyperventilation far outweighs any compensation that could be awarded by the courts. Irreparable psychological damage can be the result of the exercise which is on occasions generated by an ex-asbestos worker reacting to media advertisements generated by solicitors. The development of anxiety symptoms in these men could, in part at least, be prevented or greatly decreased if more emphasis was placed on the education of the ex-asbestos workers by the solicitors and organisations responsible for the initiation of civil actions.

\section{MRCPCH REVISION COURSES}

\section{Please advise your paediatric trainee colleagues}

\section{VIDEO COURSE \\ 24 January $201 \mathrm{I}$ \\ - Fee: $£ 200$ (includes 70 high-quality videos)

\author{
ETHICS AND COMMUNICATION \\ SKILLS COURSE \\ 25-26 January 20 I I \\ - Fee: $£ 300$ (communication scenarios, \\ including phone conversations)
}

Details and online booking: http://events.rcpe.ac.uk.

Tel: 0I3I 2473607

Fax: 013। 2204393

Email: c.gray@rcpe.ac.uk 